\title{
PERANCANGAN KAMPANYE SOSIAL MENINGKATKAN MINAT BACA ANAK MELALUI BAPUSIPDA DI KOTA BANDUNG
}

\author{
Farahdini Amalia Untarni ${ }^{1}$, Yanuar Rahman ${ }^{2}$ \\ 1,2Fakultas Industri Kreatif, Universitas Telkom
}

\begin{abstract}
Abstrak: Permasalahan mengenai minat baca anak merupakan hal yang penting untuk diperhatikan karena dapat menentukan indeks kemajuan bangsa. Telah banyak media yang membahas minat baca anak Indonesia, namun sampai saat ini hal tersebut masih tergolong rendah dan belum mengalami peningkatan yang signifikan, salah satu faktornya adalah kegiatan membaca belum menjadi sebuah kebutuhan primer. Usaha pemerintah Jawa Barat untuk meningkatkan minat baca anak adalah dengan mendirikan perpustakaan daerah BAPUSIPDA (Badan Perpustakaan dan Arsip Daerah Provinsi Jawa Barat) yang dilengkapi ruang baca anak yang tergolong nyaman dan menyediakan berbagai macam buku. Namun, sampai saat ini masyarakat belum menggunakannya secara maksimal. Hal tersebut dikuatkan dengan fenomena pengunjung anak yang datang ke perpustakaan terbilang sedikit. Untuk menganalisis dan menjawab permasalahan tersebut, terdapat beberapa tahap yang dilakukan mulai dari pengumpulan data melalui instrumen studi pustaka, kuesioner, wawancara hingga observasi lapangan. Kemudian digunakan analisis matriks perbandingan untuk membandingkan dengan kampanye sosial lain yang serupa. Dari data dan analisis tersebut, dilakukan perancangan kampanye sosial yang bertujuan untuk meningkatkan minat baca anak melalui BAPUSIPDA di kota Bandung. Dengan adanya perancangan kampanye sosial ini minat baca anak umur delapan hingga dua belas tahun yang berada di kota Bandung akan meningkat sehingga dapat tercipta budaya membaca sejak dini.
\end{abstract}

Kata kunci: minat baca anak, perpustakaan, kampanye sosial, Jawa Barat

Penulis adalah mahasiswa dan dosen program studi Desain Komunikasi Visual di Universitas Telkom, email: farahdiniamalia@gmail.com, vidiyan@telkomuniversity.ac.id 


\begin{abstract}
Concerns about the child's interest in reading is important enough to be considered because it can determine the index of the nation's progress. There has been a lot of media that addresses about the child's interest in reading in Indonesia, but until today it is still relatively low and has not experienced a significant improvement, one of the cause is the reading habit has not been a primary need. West Java government's efforts to improve children's interest in reading is build a regional library BAPUSIPDA (Library and Archives of West Java Province) equipped with a reading room for children, which is really comfortable and provide a wide range of books. However, the library has not been used optimally. It is evident from the small number of children visitors. To analyze and answer these problems, there are some steps to be done through multiple methods such as literature review, questionnaires, interviews and observation. Then, the matrix analysis comparison was conducted to compare with other social campaigns on similar activities, it is also to compare the use of design theory in the design process. From the results of the data and analysis, the authors designed a social campaign with the aim to improve the children interest in reading in the BAPUSIPDA library. With this campaign, children's reading interest at ages 8 to 12 years in Bandung will increased, this intended to create a culture of reading from an early age.
\end{abstract}

Keywords: children's reading interest, library, social campaign, West Java

\title{
PENDAHULUAN
}

Era globalisasi turut mempengaruhi perkembangan ilmu pengetahuan yang begitu pesat, tak lagi dalam hitungan tahun, bulan, atau hari tetapi telah menjadi jam bahkan detik. Salah satu cara untuk mendapatkan pengetahuan adalah dengan cara membaca. Melalui proses membaca kita dapat menambah wawasan, melatih fungsi otak dan meningkatkan konsentrasi. Proses membaca juga dapat menjadi penentu kemajuan sebuah bangsa, semakin tinggi minat baca maka semakin maju pula negara tersebut.

Menurut Menteri Pendidikan dan Kebudayaan, minat baca di Indonesia memang masih rendah. Data United Nations Educational, Scientific and Cultural Organization (UNESCO) tahun 2012 menyebutkan bahwa minat baca di Indonesia hanya 0.001 persen (republika.co.id) dan menurut Internasional Education 
Achievement (IEA) melaporkan bahwa kemampuan membaca anak SD di Indonesia berada di urutan 38 dari 39 negara peserta studi (www.digilib.um.ac.id).

Masalah minat baca di Indonesia memang telah banyak dibicarakan di koran, majalah, makalah, dan artikel internet. Namun ironisnya sampai saat ini belum ada peningkatan yang signifikan. Idealnya minat baca memang diajarkan sejak dini dan terus diawasi oleh orangtua. Proses mengajarkan membaca untuk anak seharusnya dibuat menyenangkan dan tidak dipaksakan agar tidak bosan dan tidak merasa tertekan.

Salah satu kendala mengapa minat baca di Indonesia rendah adalah harga buku yang dijual terlalu mahal dibandingkan dengan negara maju seperti Jepang. Mahalnya harga buku di Indonesia diakui oleh Ketua Umum Ikatan Penerbit Indonesia (IKAPI), beliau mengatakan bahwa pajak kertas yang tinggi membuat penerbit tidak mau memberikan harga yang sesuai dengan biaya produksi mencetak buku.

Untuk mengantisipasi hal ini, salah satu cara yang dilakukan Pemerintah melalui Badan Perpustakaan dan Arsip Daerah (BAPUSIPDA) Jawa Barat adalah dengan mendirikan perpustakaan yang dapat dijadikan tempat nyaman untuk membaca dengan dilengkapi dengan fasilitas ruang baca anak yang menarik, hal ini ditujukan untuk meningkatkan minat baca anak di Indonesia. Di dalam BAPUSIPDA ruang baca anak memiliki banyak koleksi buku cerita, gambar kartun dan terkadang ada pemutaran film yang dapat membuat anak merasa nyaman. Perpustakaan BAPUSIPDA juga menyediakan mobil perpustakaan keliling bernama Words of Wheels yang beroperasi di taman Tegallega dan lapangan Sabuga pada hari minggu sejak pukul 06.00 hingga 12.00 .

Namun sayang usaha Pemerintah dalam meningkatkan minat baca dan keinginan masyarakat, khususnya anak-anak untuk mengunjungi perpustakaan belum mengalami peningkatan yang signifikan. Data dari BAPUSIPDA pengunjung ruang baca anak pada bulan Desember 2015 hanya naik 0.002 pesen dari bulan 
sebelumnya dan 0.5 dari Desember 2014. Jumlah tersebut belumlah memenuhi target dari BAPUSIPDA.

Berdasarkan fakta dan masalah dalam pembahasan diatas, dirasa perlu adanya sosialisasi yang bertujuan untuk meningkatkan minat baca anak Indonesia umur 8 hingga 12 tahun. Perancangan kampanye sosial ini menarik untuk dikaji karena anak usia 8 hingga 12 tahun di Bandung telah lancar membaca dan dapat menentukan pilihannya hingga dapat dimotivasi untuk membudayakan kebiasaan gemar membaca. Data dikumpulkan dengan cara observasi ke perpustakaan BAPUSIPDA dan perpustakaan keliling, wawancara dengan narasumber, kuesioner dan studi pustaka. Kampanye sosial yang menyuarakan minat baca anak umur 8 hingga 12 tahun ini diharapkan dapat meningkatkan budaya membaca anak dengan tingkat yang cukup signifikan.

\section{KAJIAN TEORI}

Dalam perancangan media, seorang desainer haruslah memiliki dasar teori yang dijadikan pedoman pembuatan media. Kampanye sosial menurut Antar Venus dalam buku "Manajemen Kampanye Panduan Teoretis dan Praktis dalam Mengefektifkan Kampanye Komunikasi" (2012:9-10) adalah kegiatan komunikasi yang dilakukan secara terlembaga. Penyelenggara kampanye umumnya bukanlah individu melainkan lembaga atau organisasi. Lembaga tersebut dapat berasal dari lingkungan pemerintah, kalangan swasta atau lembaga swadaya masyarakat. Menurut Charles U. Larson (1992) dalam Venus (2012:11) kampanye sosial dibagi menjadi tiga kategori, yaitu Product-oriented Campaigns, Candidate-oriented campaign, dan Ideologically or cause oriented Campaigns.

Komunikasi menurut Miller (1996) dalam Suryanto (2015:51) merupakan center of interest yang ada dalam situasi perilaku manusia yang memungkinkan suatu sumber secara sadar mengalihkan pesan kepada penerima dengan tujuan mempengaruhi perilaku tertentu. Komunikasi menurut Laswell dalam Suryanto 
(2015:54) memiliki lima komponen yaitu, siapa, mengatakan apa, kepada siapa, melalui saluran apa dan akibatnya apa. Fungsi dari komunikasi menurut Widiatama (2011:43-46) ada tiga yaitu, informasi, mengajak dan mengingatkan. Dalam perancangan kampanye sosial seorang desainer memiliki suatu dasar teori perancangan media, meliputi, tipografi, warna, ilustrasi dan layout.

\section{METODE PENELITIAN}

Penelitian dimulai dari studi pustaka tentang data dan fakta terkini mengenai budaya membaca anak-anak Indonesia, kemudian dilakukan observasi ke beberapa sekolah untuk melihat secara langsung perilaku siswa dan melakukan wawancara dengan guru serta orang tua siswa. Selain itu juga dilakukan kunjungan ke perpustakaan BAPUSIPDA untuk meninjau program terdahulu yang kontekstual dengan tujuan penelitian secara komprehensif. Analisis matriks juga digunakan untuk membandingkan program kampanye sejenis yang pernah dilaksanakan oleh beberapa organisasi dalam bidang yang serupa. Analisis ini digunakan untuk menentukan kelebihan dan kekurangan kampanye yang pernah berjalan

\section{HASIL DAN DISKUSI}

Hasil wawancara dengan ibu Ena Ratna Irawati selaku pustakawan BAPUSIPDA yang telah berpengalaman dibidang minat baca, menyebutkan bahwa usia anak diajarkan belajar membaca ketika telah menginjak usia sekolah dasar, karena pada usia tersebut anak telah dapat menyerap banyak informasi. Menurut beliau kegiatan membaca merupakan hal yang sangat penting diajarkan karena dapat menentukan kemajuan bangsa. Sebutan gemar membaca dapat dilihat dari berapa lama dan berapa banyak jumlah buku yang dibaca dalam satu bulan. Jumlah yang dapat dijadikan indikator anak tersebut gemar membaca adalah 4 hingga 5 buku perbulan. 
Pada proses pembuatan media kampanye sosial ini data dikumpulkan dari perpustakaan BAPUSIPDA yang berada di Jalan Kawaluyaan II No. 4, SoekarnoHatta Bandung. Dari data perpustakaan BAPUSIPDA pengunjung ruang baca anak menduduki peringkat terakhir dibandingkan ruang baca remaja dan dewasa.

Berdasarkan data diatas, perancangan kampanye sosial ini ditujukan oleh target primer yaitu anak-anak laki-laki dan perempuan usia 8 hingga 12 tahun yang telah lancar membaca, dan dapat menentukan pilihannya sebagai pelajar yang tinggal di kota Bandung. Target sekunder dari perancangan kampanye sosial ini adalah orangtua yang memiliki anak berusia 8 hingga 12 tahun, berusia diatas 20 tahun keatas yang memiliki status ekonomi menengah dan menengah keatas, berada di kota Bandung dan dapat menjadi pendorong sang anak meningkatkan minat baca.

Ditemukan beberapa kampanye sosial yang membahas persoalan yang sama mengenai minat baca, dan mencoba menerangkannya menjadi sebuah matriks perbandingan.

Tabel 1 Matriks Perbandingan Kampanye Berdasarkan Kegiatan

\begin{tabular}{|c|c|c|c|}
\hline & Sosialisasi BAPUSIPDA & Kampanye Kebukit & $\begin{array}{c}\text { Kampanye Relawan } \\
\text { Rumah Baca }\end{array}$ \\
\hline Logo & & & \\
\hline Kegiatan & $\begin{array}{l}\text { Sosialisasi ke masyarakat } \\
\text { mengenai gemar baca }\end{array}$ & $\begin{array}{l}\text { Mengajak untuk } \\
\text { membaca dan } \\
\text { membangun } \\
\text { perpustakaan untuk } \\
\text { tempat terpencil }\end{array}$ & $\begin{array}{l}\text { - Mengajak anak untuk } \\
\text { suka membaca } \\
\text { - Mendirikan ruang baca } \\
\text { di Taman } \\
\text { - Mendonasikan buku } \\
\text { interaktif ke pulau- } \\
\text { pulau di Jakarta }\end{array}$ \\
\hline $\begin{array}{l}\text { Tujuan } \\
\text { Kegiatan }\end{array}$ & $\begin{array}{l}\text { Memberitahukan bahwa } \\
\text { membaca adalah kegiatan } \\
\text { yang penting }\end{array}$ & $\begin{array}{l}\text { - Menyediakan sarana } \\
\text { membaca } \\
\text { - Membangun karakter } \\
\text { bangsa untuk } \\
\text { senantiasa membaca }\end{array}$ & $\begin{array}{l}\text { Membantu anak-anak } \\
\text { kepulauan agar tetap } \\
\text { dapat belajar dan } \\
\text { membaca }\end{array}$ \\
\hline
\end{tabular}




\begin{tabular}{|c|c|c|c|}
\hline $\begin{array}{l}\text { Seg- } \\
\text { mentasi }\end{array}$ & Masyarakat umum & Pelajar (SD - Mahasiswa) & $\begin{array}{l}\text { Anak-anak yang putus } \\
\text { sekolah dan masyarakat } \\
\text { umum }\end{array}$ \\
\hline Media & $\begin{array}{l}\text { - X-banner } \\
\text { - Twitter }\end{array}$ & $\begin{array}{l}\text { - Media sosial dengan } \\
\text { \#NusantaraMembaca } \\
\text { - Banner } \\
\text { - X-banner }\end{array}$ & $\begin{array}{l}\text { - Media sosial dengan } \\
\text { \#MariBerbagi }\end{array}$ \\
\hline Lokasi & Jawa Barat & Indonesia & Jakarta \\
\hline
\end{tabular}

Sumber : Analisis Pribadi

Tabel 2 Perbandingan Kampanye Berdasarkan Teori Desain

\begin{tabular}{|c|c|c|c|}
\hline & Sosialisasi BAPUSIPDA & $\begin{array}{c}\text { Kampanye } \\
\text { \#NusantaraMembaca }\end{array}$ & Kampanye \#MariBerbagi \\
\hline Logo & & & \\
\hline Warna & $\begin{array}{l}\text { Kampanye sosialisasi yang } \\
\text { dilakukan oleh pihak } \\
\text { BAPUSIPDA tidak memiliki } \\
\text { logo. Namun, media yang } \\
\text { digunakan untuk mengajak } \\
\text { membaca dan datang ke } \\
\text { perpustakaan } \\
\text { menggunakan warna } \\
\text { biru.Warna biru yang } \\
\text { dominan melambangkan } \\
\text { ketenangan dan teknologi, } \\
\text { karena perpustakaan } \\
\text { BAPUSIPDA telah } \\
\text { dilengkapi teknologi yang } \\
\text { bagus. }\end{array}$ & $\begin{array}{l}\text { Penggunaan warna oren } \\
\text { dan merah yang } \\
\text { digunakan oleh kebukit } \\
\text { melambangkan kesan } \\
\text { menyenangkan ketika } \\
\text { membaca buku. Warna } \\
\text { oren yang terkesan } \\
\text { optimis dan ceria dan } \\
\text { merah melambangkan } \\
\text { kecintaan terhadap } \\
\text { buku. }\end{array}$ & $\begin{array}{l}\text { Kampanye Mari Berbagi } \\
\text { menggunakan warna } \\
\text { hijau dan kuning. Warna } \\
\text { tersebut digunakan } \\
\text { untuk membuat kesan } \\
\text { bahwa } \\
\text { membaca kegiatan } \\
\text { kegiatan adalah } \\
\text { menyenangkan. Warna } \\
\text { hijau melambangkan } \\
\text { alami daerah kepulauan } \\
\text { dan warna kuning } \\
\text { melambangkan optimis } \\
\text { serta keceriaan. }\end{array}$ \\
\hline Tipografi & $\begin{array}{l}\text { Tipografi yang digunakan } \\
\text { oleh sosialisasi yang } \\
\text { dilakukan BAPUSIPDA } \\
\text { adalah tipe sans serif } \\
\text { sehingga mudah dibaca, } \\
\text { jelas dan tidak terkesan } \\
\text { formal. }\end{array}$ & $\begin{array}{l}\text { Tipografi yang digunakan } \\
\text { oleh Kebukit adalah tipe } \\
\text { sans serif. Menggunakan } \\
\text { jenis huruf ini terkesan } \\
\text { bersahabat dan tidak } \\
\text { formal. }\end{array}$ & $\begin{array}{l}\text { Tipografi yang digunakan } \\
\text { oleh Relawan rumah baca } \\
\text { adalah tipe sans serif. } \\
\text { Terkesan lebih friendly } \\
\text { kepada masyarakat. } \\
\text { Menggunakan tipe ini } \\
\text { telihat lebih jelas dan } \\
\text { terkesan tidak formal. }\end{array}$ \\
\hline Ilustrasi & $\begin{array}{lr}\text { Banyak menggunakan } \\
\text { ilustrasi } \\
\text { perpustakaan. }\end{array}$ & $\begin{array}{l}\text { Dalam logo kebukit } \\
\text { menggunakan ilustrasi } \\
\text { buku yang dibalik. Dalam } \\
\text { media menggunakan } \\
\text { ilustrasi tumpukan buku }\end{array}$ & $\begin{array}{l}\text { Dalam logo relawan } \\
\text { rumah baca terdapat } \\
\text { ilustrasi gabungan antara } \\
\text { atap rumah dan buku. } \\
\text { llustrasi tersebut } \\
\text { menandakan adanya }\end{array}$ \\
\hline
\end{tabular}




\begin{tabular}{|c|c|c|c|}
\hline & & $\begin{array}{l}\text { yang disusun rapi disisi } \\
\text { media. }\end{array}$ & $\begin{array}{l}\text { tempat yang nyaman } \\
\text { untuk membaca buku. } \\
\text { Untuk media, relawan } \\
\text { rumah baca banyak } \\
\text { menggunakan ilustrasi } \\
\text { anak-anak yang sedang } \\
\text { membaca. }\end{array}$ \\
\hline Layout & $\begin{array}{l}\text { Layout yang digunakan } \\
\text { untuk media leaflet adalah } \\
\text { Sircus layout karena tata } \\
\text { letak yang tidak beraturan } \\
\text { dan terkesan kurang rapi. }\end{array}$ & $\begin{array}{l}\text { Layout yang digunakan } \\
\text { oleh Kebukit adalah tipe } \\
\text { Jumble Layout karena } \\
\text { tipografi dan ilustrasi } \\
\text { disusun berada ditengah } \\
\text { dan terlihat rapi. } \\
\text { Media } \\
\text { \#NusantaraMembaca } \\
\text { menggunakan tipe } \\
\text { Jumble Layout, karena } \\
\text { antara tipografi dan } \\
\text { ilustrasi terlihat teratur } \\
\text { dan rapi. }\end{array}$ & $\begin{array}{l}\text { Layout yang digunakan } \\
\text { pada logo adalah Jumble } \\
\text { layout karena tipografi } \\
\text { dan ilustrasi diletakkan } \\
\text { ditengah dan terlihat } \\
\text { rapi. } \\
\text { Pada media poster } \\
\text { relawan rumah baca } \\
\text { menggunakan tipe Copy } \\
\text { heavylayout karenalebih } \\
\text { banyak tipografi } \\
\text { dibandingkan dengan } \\
\text { ilustrasinya. }\end{array}$ \\
\hline
\end{tabular}

Sumber : Analisis Pribadi

Berdasarkan hasil analisis kedua matriks tersebut beberapa kesimpulan yang dapat diambil adalah: adanya urgensi untuk memberitahukan pada masyarakat khususnya generasi muda tentang pentingnya membaca. Proses pemberitahuan informasi ini dapat dilakukan melalui kampanye yang dirangkai melalu beberapa aktivitas maupun media agar berjalan efektif. Selain ditujukan bagi anak-anak kampanye ini perlu dukungan dari orang tuan dan sekolah agar dampaknya bisa lebih optimal. Untuk meningkatkan kegiatan gemar membaca bisa dilakukan oleh siapapun dan dimanapun mulai dari anak-anak hingga orang tua, mulai dari rumah hingga perpustakaan seperti BAPUSIPDA.

\section{Konsep Perancangan}

Perancangan ini ditujukan untuk meningkatkan minat baca anak usia 8 hingga 12 tahun. Pesan yang disampaikan dalam perancangan kampanye sosial ini adalah mengajak anak untuk mengunjungi dan membaca buku di perpustakaan BAPUSIPDA. Nama kampanye sosial ini adalah: "Baca di perpus yuk!" kata 
tersebut dipilih karena mengandung kata ajakan dan terkesan bahasa sehari-hari yang sering digunakan oleh anak-anak. Dalam perancangan kampanye sosial ini menggunakan tiga tahap proses komunikasi, yaitu informing, persuading dan reminding.

Konsep kreatif dalam perancangan kampanye sosial ini adalah menggunakan brand archetype dan gamification. Brand archetype yang digunakan dalam perancangan media adalah fun, kreatif dan imajinasi. Gamification dalam konsep kreatif adalah memanfaatkan merchandise sebagai alat untuk menarik perhatian anak agar sering meminjam dan membaca buku. Metode ini mengajak anak untuk mengunjungi perpustakaan dan meminjam buku. Merchandise yang dibagikan ada beberapa yakni, (1) pin, (2) notebook dan (3) kaos. Pin akan diberikan setelah anak meminjam 7 buku, notebook untuk anak yang telah meminjam 25 buku dan kaos untuk anak yang telah meminjam 70 buku.

Sesuai dengan hasil pengumpulan data, media yang sesuai dengan target sasaran dalam perancangan kampanye sosial ini adalah media sosial, poster, banner, $x$-banner, baliho, brosur, stiker, pembatas buku, $t$-shirt, dan merchandise.

Dalam konsep visual perancangan kampanye sosial ini, menggunakan tiga unsur yaitu buku, anak-anak dan tokoh representasi. Ilustrasi yang digunakan dalam perancangan kampanye ini adalah kartun sederhana. Ilustrasi tersebut dipilih agar target tidak sulit memahami isi pada media. Warna yang digunakan adalah warna cerah agar anak-anak tertarik untuk melihat media kampanye sosial ini. Layout yang digunakan dalam perancangan ini menggunakan layout dengan komposisi yang seimbang agar terlihat menarik. Tipografi yang digunakan dalam perancangan ini adalah tipe sans serif yang terkesan tidak kaku dan memiliki tingkat keterbacaan yang jelas. Bahasa yang digunakan adalah bahasa tidak formal yang sering digunakan oleh anak-anak dalam kehidupan sehari-hari. 


\section{Hasil Perancangan}

Dalam perancangan kampanye sosial ini terdapat Logo Kampanye

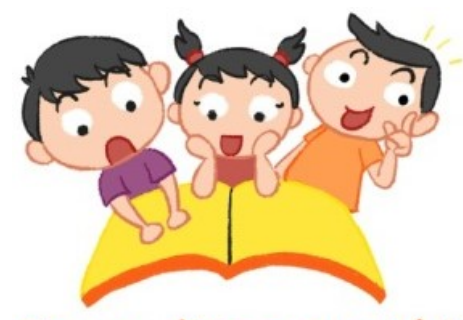

\section{Baca di Perpus Yuk!}

jadi penasaran, jadi tau, jadi pinter

\section{Gambar 1 Logo Kampanye}

Sumber : Dokumentasi Pribadi

Maskot Kampanye Sosial

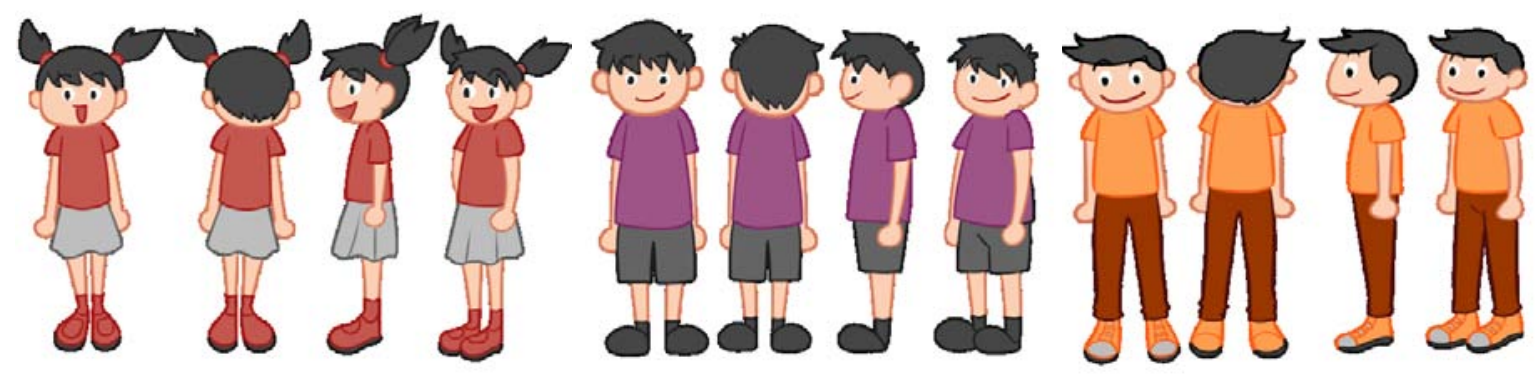

Gambar 2 Karakter Hauna, Daud dan Alaric

Sumber : Dokumentasi Pribadi

Media Perancangan Kampanye Sosial
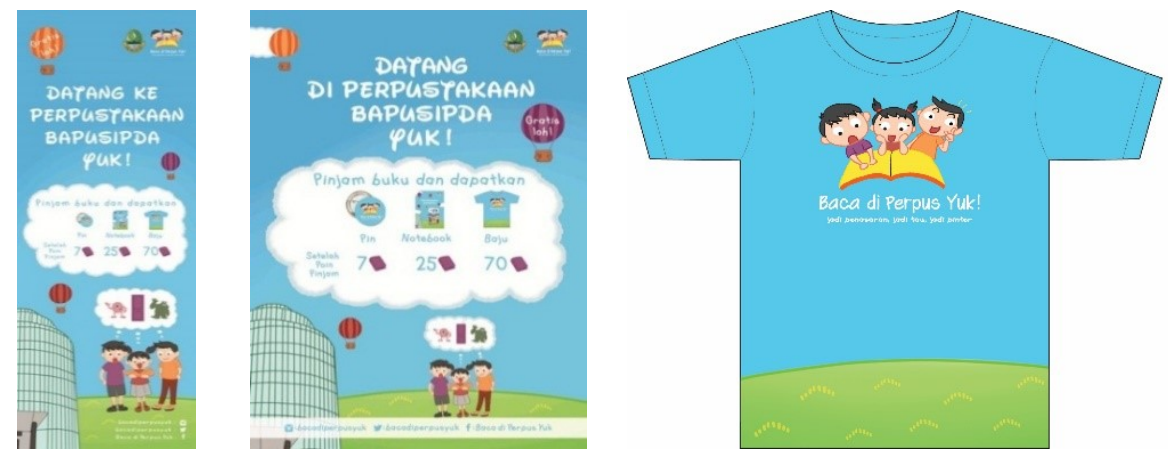

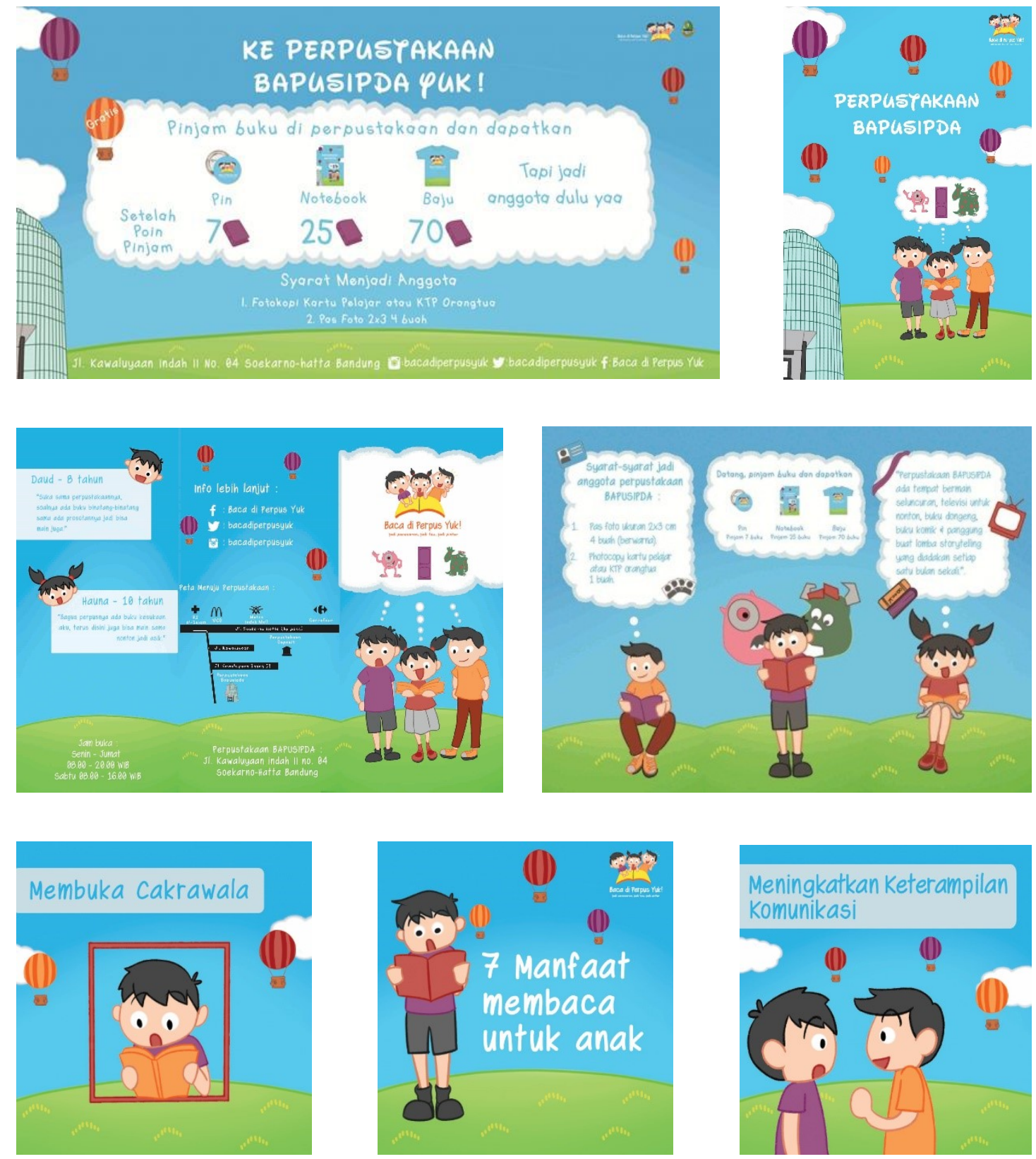

Gambar 3 Rangkaian Media Kampanye Sosial

Sumber : Dokumentasi Pribadi

\section{KESIMPULAN}

Berharap dengan adanya kampanye sosial "Baca di perpus yuk!" pengunjung anak usia 8 hingga 12 tahun di perpustakaan BAPUSIPDA bertambah, 
yang baik secara langsung maupun tidak langsung dapat mempengaruhi peningkatan minat baca anak pada usia tersebut. Perancangan media kampanye sosial ini juga bertujuan untuk memperbaiki media yang telah ada agar lebih tepat sasaran, dan lebih jauh lagi masyarakat luas terutama anak-anak akan lebih tertarik mengunjungi perpustakaan BAPUSIPDA.

\section{DAFTAR PUSTAKA}

Soewardikoen, Didit Widiatmoko., 2013. Metodologi Penelitian Visual dari Seminar ke Tugas Akhir. Bandung: CV Dinamika Komunika.

Suryanto, 2015. Pengantar Ilmu Komunikasi. Bandung: Pustaka Setia.

Venus, Antar., 2012. Manajemen Kampanye Panduan Teoretis dan Praktis dalam Mengefektifkan Kampanye Komunikasi. Bandung: Simbiosa Rekatama Media.

Widiatama, Rendra., 2011. Teknik Menulis Naskah Iklan. Yogyakarta: Cakrawala. 